\title{
Do Bifrontismo de Jano: Notas para a reflexão sobre os processos de Reflexividade, Síntese e Re-Significação de Memórias Sociais
}

\section{Rosevel Gutemberg Silva*}

Resumo: Este artigo trata de alguns "efeitos" verificados no âmbito da re-produção de identidades na fase avançada da modernidade. De modo mais específico, pretende-se averiguar alguns matizes decorrentes do "encontro", "interação" de distintas alteridades e seus correlatos planos de significação primários. Das situações de convívio favoráveis ao desenvolvimento de sínteses criativas, depreende-se terreno fértil de análise de complexos processos mnemônicos, recursivos, que incidem, propiciam as reproduções de instituições, valores e práticas sócio-culturais, bem como o desenvolvimento de sentidos e ações para atualizá-las em novos moldes. É destas "diferencialidades" que trataremos, vistas a partir dos "sujeitos", o que "são" definidos a partir de sua auto-percepção e de suas dinamizações cotidianas, ancoradas em estoques mnemônicos, herdados ou adquiridos. O peso e a medida desta proposta metodológica serão dadas pela recente história de síntese e criatividade do mundo candomblecista, em mediação com outras conformações de grupo.

Palavras-chave: Memória, Recursividade, Identidade, Interações, Plasticidade, Síntese

\begin{abstract}
The present essay is about some verified effects in the identities reproduction field of the latest phase of modernity. It's, specifically, pretended to verify some of the nuances that arise from the meetings or interactions among different otherness and their correlated plans of primary signification. From situations of people living together that collaborate to the development of creative synthesis, arise a fertile camp of analysis of complex mnemonics process that allows the reproduction of institutions, values and social-cultural practices, as well as the development of meanings and actions for new models. That is the issue of this article: the differences seen from the point of the subjects, considering how they define themselves from their self-perception and from their daily life, based on inherited or acquired mnemonics resources. The methodological frame of this proposal is given by the recent history of synthesis and creativity of the "Candomblé" world in their interaction with other groups.
\end{abstract}

Key-words: Memory, Identity, Interactions, Plasticity, Synthesis.

\footnotetext{
* Mestre em Sociologia pela Universidade de Brasília (UnB). Atualmente encontrase em doutoramento na mesma instituição. E-mail: rosevel81@hotmail.com
}

Latitude, vol. 3, n², pp. 65-82, 2009.

DOI: https://doi.org/10.28998/2179-5428.20090204 
Do Bifrontismo de Jano: Notas para a reflexão sobre os processos de Reflexividade, Síntese e Re-Significação de Memórias Sociais

\section{Cada dia que passa incorporo mais esta verdade, de que eles não [vivem senão em nós e por isso vivem tão pouco; tão intervalado; tão débil. fora de nós é que talvez deixaram de viver, para o que se chama \\ [tempo. \\ (...) ou talvez existamos somente neles, que são omissos, e nossa \\ [existência, apenas uma forma impura de silêncio, que preferiram.}

Do Poema "Convívio" Carlos Drummond de Andrade

\section{Introdução}

Talvez não haja liame mais eficaz entre a ação dotada de sentido e seus motivadores primários, conscientes ou inconscientes, senão aquele que reside na capacidade "humana" de reter, incorporar, sentir por meio de símbolos, mitos ou regimes discursivos. Depende do ponto de vista, de quem fala, de "onde" se fala e das circunstâncias enredadas. Sem a referência às qualidades temporais e espaciais, e de suas características situacionais-históricas, incorreríamos no risco de cair numa armadilha de naturalização das muitas formas de organização e gestão da linguagem e da sensibilidade humanas. Sem nos subsumir a um universalismo humanista, pretendo apenas esboçar um exercício sociológico que tente colocar em relação os atos de simbolização e significação como práticas sincrônicas de aquisição e aprendizado de dinâmicas sociais específicas ao mesmo tempo em que a re-produção de potencialidades formativas.

De outro prisma, os sujeitos, formados mediante distintos planos cognitivos, informados e incorporados que são de princípios orientadores, de éticas, de memórias sociais, aprendem e apreendem as "regras do jogo" mediante a participação efetiva em nichos específicos de sociabilidade, e tendem, invariavelmente, a devolver ou contribuir, na transformação mesma das arenas em que se movem. Na maior parte das vezes, reconfigurações sutis processadas intergeracionalmente.

Mas uma característica marcante inaugurada pela modernidade e acelerada exponencialmente após a revolução industrial e durante a chamada modernidade tardia é o crescente esborramento de planos de significação nos espaços sociais. Melhor seria dizer que as fronteiras tenderam, cada vez mais, a se tornarem opacas, quando não deslocadas ou à guisa de marcação. Cada vez menos instituições como a família ou o Estado podem conferir um sentimento abarcante ou completo de participação e identidade aos sujeitos.

Os espaços de formação tendem a ser multiformes e atravessados por distintas linguagens que acabam, ao cabo, conferindo tônicas novas nos modos de sociabilidade e interação. Espaços marcados pelos trânsitos de alteridades diversas, como algumas megalópoles, locais privilegiados para se analisar tais fenômenos. No entanto, não se pretende aqui fazer uma análise dos "espaços globais", mas 
antes atentar para alguns efeitos "localizados" de alguns modos de subjetividade possibilitados pelo "encontro" de distintas alteridades na conformação de uma certa visão de mundo, mais especificamente, na constituição de uma arena de "possíveis" sujeitos no mundo dos candomblés.

A proposta é tentar entrelaçar alguns dos fatores conformadores de subjetividades homólogas no interior do campo candomblecista de Salvador. Parte-se do pressuposto de que as práticas rituais e cotidianas, com distintos matizes, marcam modos correlatos de agenciar as crenças que lhe dão sustentabilidade e validade. A vinculação entre modos de leituras possíveis (interpretações) da vida e os "estoques de memória social" (acervo) é o foco de análise. Tal proposta se pauta pelo interesse em entender modos de subjetivação, ou seja, como os agentes, dotados de capacidade cognitiva e interpretativa, agenciam, seletivamente sua conduta, com vista à maximização de "rendimentos", simbólicos, afetivos, ou econômicos.

A idéia de trabalhar com a noção de acervo pode ser polêmica, por talvez conotar um conjunto de conhecimentos prontos e estanques a serem sacados e utilizados em eventos ou disposições de ações bem definidas. Mas o uso que se fará desta noção aqui, pressupõe antes a capacidade dos agentes de fazerem uso de "disposições de saberes" mediante a leitura adequada da situação. Nesse sentido, o acervo é pensado como o conjunto de disposições para as práticas "incorporadas" pelos indivíduos, e que, ao cabo, constituem uma memória ao mesmo tempo coletiva e individual, haja vista que a leitura e sua reverberação nas práticas só podem se dar subjetiva e individualmente.

A mimesis não age por mera repetição, antes por condensação e deslocamento. Os "encontros possíveis" das subjetividades e seus rebatimentos, por assim dizer, conformam os planos societais. Não obstante, a recorrência de certos traços, do reconhecimento e identificação de signos, o seu manejo, a existência de instituições duráveis, é o que confere o caráter sócio-antropológico da interpretação e participação ativas dos eventos. Mas, na tentativa de compreender como se processam mutações nos modos de entendimento, produção e comunicação social (disposições duráveis), devemos nos deter no que há de mais caracteristicamente humano, o aspecto que implica nos impulsos constantes para a subjetivação, que opera entre a reprodução, a interpretação ${ }^{1}$ e a recriação dos valores e das práticas sociais cotidianas.

${ }^{1}$ Os experimentos de Garfinkel (s/d) e sua visada etnometodológica apontam assim para a característica comum entre as experiências do senso comum e as da prática científica. Na sua concepção os atores agem racionalmente em suas práticas cotidianas, orientados por um senso prático - plástico mesmo. Ao se depararem com situações imprevistas, que quebram com a previsibilidade da ação, têm a chance de atualizarem a sua bagagem sócio-simbólica e sócio-interativa. $\mathrm{O}$ aspecto etnometodológico em foco se dá pela tentativa de apreender as propriedades racionais das expressões indexicais e de outras ações práticas como contingente de realizações práticas astutamente organizadas da vida cotidiana. Foi fortemente influenciado pela abordagem fenomenológica de Alfred Schutz, o qual, por sua vez, é influenciado por Henri Bergson e Edmund Hussel. 
Do Bifrontismo de Jano: Notas para a reflexão sobre os processos de Reflexividade, Síntese e Re-Significação de Memórias Sociais

\section{Durée: Marcação de ritmos temporais e definição de espaços}

Vele a pena, nesse instante, reportarmo-nos à retomada da noção de durée por parte de Anhony Giddens. Para este autor, a noção de durée funciona de modo semelhante à noção de tempo reversível do Lévi-Strauss, pois seja lá o que for o "tempo", os eventos e rotinas da vida cotidiana não funcionam numa "mão de via única". Daí que ao remontar o seu esquema, Giddens aluda para a importância dos termos "reprodução social" e "recursividade", cujo intuito reside em "relembrar" o caráter repetitivo da vida cotidiana. Reafirma ainda a diferencialidade da durée, a sua dualidade, ao distinguir a durée da vida individual da durée das instituições (longue durée). Esta dualidade estruturante pode nos servir para pensar as muitas disposições possíveis e qualificáveis de um tipo ideal da família patriarcal, por exemplo. Em um plano histórico de longa duração, o que significaria pensar nas reconfigurações extensas em torno dos modos de dominação, ou de associação, que repousaram no modelo patriarcal? Obviamente que pensar no modelo de família patriarcal implica reduzir ao máximo o conceito de pai, quase no sentido de encontrar um mito ${ }^{2}$. Isto não pode se dar senão como um "recurso" à sistematização de derivações possíveis de um modelo reduzido, ao cabo, como exercício de síntese ${ }^{3}$. Daí Giddens afirmar que o tempo da vida individual é

2 Não se tomará o mito aqui como na psicanálise freudiana, para a qual todas as produções míticas são variações e disfarces do tema da sexualidade, nem tampouco na versão estruturalista segundo a qual há um substrato lógico e inconsciente da cultura que atua como código das conduta, Antes será tomado como a combinação de elementos teóricos e elementos de criação artísticas, como na acepção de Cassirer. Segundo este autor a atitude metodológica do mito é a de se processar por uma redução intelectual, fazendo derivar dos fatos a teoria em um todo homogêneo. A rigor, a imaginação mítica requer um ato de crença. Afinal, a crença no inconsciente e dos seus rebatimentos em consonância com a sexualidade não constituem princípios operadores na própria prática psicanalítica de diagnóstico e tratamentos dos distúrbios por ela identificados, classificados e qualificados? Ou ainda, toda a sorte de produção para o consumo na modernidade não parece ser desencadeado por um impulso irrefreável da crença no progresso? Muitas das tradições nacionais, senão todas, almejaram incutir nos membros dos seus grupos a crença de uma origem comum, de um traço característico, na tentativa de sustentar a sua existência enquanto comunidade extensa, erigindo fronteiras de demarcação da identidade.

${ }^{3}$ Tomemos, por ora, a proposição antropológica de Sir James Frazer de que não há qualquer limite claro que cinda cabalmente a arte mágica dos nossos modos de pensamento científico. Em suma, no seu entendimento a magia também é científica em seus fins, embora seja uma "ciência elusiva", uma "pseudociência". (Frazer apud Cassirer, 2005, p. 127). Sem reduzir o mito à condição de fatores etiológicos e explicativos, a elementos estáticos da conduta, esforcemo-nos por vê-lo em sua plasticidade e mobilidade, em seu princípio dinâmico. Ao aceitar de Cassirer a 
irreversível enquanto que o da longue durée é reversível. Se as instituições mais duráveis só existem e resistem por meio da reprodução de práticas cotidianas assentadas na crença de sua validade, mas constantemente deslocadas e reinterpretadas inter-geracionalmente, é porque, ao mesmo tempo em que constituem e impelem os sentidos das práticas, mediam a abertura e o impulso necessários para sua remodelação. E é por meio das interpretações dos agentes no fluxo da cotidianidade e da fugacidade dos eventos que a reversibilidade se processa. A reversibilidade da longue durée se realiza mediante atualizações possibilitadas nos atos reflexivos, sintetizadores e produtores de deslocamentos na ordem da representação e apresentação ético-moral, bem como das sensibilidades a elas vinculadas.

Analisando o esquema analítico de Giddens, especificamente no que tange ao conceito de estrutura, William Jr. (1992: 6) retoma a sua acepção de que a estrutura deve ser pensada como existência virtual de traços de memórias, uma base orgânica do entendimento:

Structures are not the patterned social practices that make up social systems, but the principles that pattern these practices. Structures, therefore, have olly what he elsewhere terms a "virtual existence". Structures do not exist concretely in time and space except as "memory traces, the organic basis of knowledgeability (i. e., only as ideas or schemas lodged in human brains) and as they are 'instantiated in action' (i. e., put into practice).

Mas somos obrigados a cogitar que a mediação não se dá por acionamentos mecânicos dos signos, antes pela capacidade de retenção de disposições para as práticas, para a incorporação de esquemas, sensório-motores, perceptivos e compreensivos do discurso e da ação social ${ }^{4}$. É nesta fenda que

proposição de vê-lo pelo ângulo da dramaticidade, de um mundo de ações e forças, de poderes conflitantes o mito está qualificado pelo seu apelo emocional. Não obstante, no seu fluxo, o que se revela é a sua estrutura dual, simultaneamente conceitual e perceptual. Tudo é visto e sentido rodeado de aura especial, marcados por sentimentos como alegria ou pesar, angústia, excitação, exultação ou depressão; os objetos são malignos ou benignos, amistosos ou hostis. E esta forma elementar de experiência humana não foi elidida nem mesmo do modo de vida do homem civilizado, pois mesmo este, quando acometido por emoções violentas, deixa saltar a superfície, na face, no corpo, o rubor, o tremor animados por sentimentos de amor ou ódio, paixão e esperança. Também o mito age por síntese, são concomitantemente explicativas e propositivas.

${ }^{4}$ Nesse sentido vale apontar para a reação de Blummer às visões não-cognitivistas que tenderam a menosprezar o papel do self, da mente e da consciência em de suas tentativas de depreendê-las, meramente, como "decorrência do hábito. Uma interessante abordagem do interacionismo simbólico foi feita por Baldwin (1988: 44-52) em seu artigo Action, Habit e Self-Counscious 
Do Bifrontismo de Jano: Notas para a reflexão sobre os processos de Reflexividade, Síntese e Re-Significação de Memórias Sociais

Norbert Elias, por exemplo, propusera pensar a "quinta dimensão social", a da consciência, em meio à triangulação entre memória, linguagem e conhecimento. Por sua própria experiência de vida, como judeu de classe média, criado e educado no seio de uma sociedade aristocrático-belicista percebe a vulnerabilidade da condição judaica em meio ao projeto civilizador em curso, mediante os escalonamentos hierárquicos reiterados nas utilizações de insígnias, distribuições de cargos e lotações profissionais e de poder de acordo com a filiação e ascendência étnica. As ondulações na balança de poder colocavam, entre-marés, os judeus em xeque, como bodes expiatórios do mito fomentador da unidade nacional alemã ${ }^{5}$. Neste caso, a mitologia comparece como uma sombra para os judeus, haja vista que impôs sérias barreiras ao processo de assimilação e integração efetiva na sociedade nacional.

A produção de estigmas é uma das contrapartidas dos processos de formação social a partir de relações assimétricas de participação e distribuição dos bens econômicos, políticos e simbólicos. O poder, desse ponto de vista, se localiza na distribuição assimétrica dos recursos disponíveis socialmente, conferindo a grupos e indivíduos neles ancorados posições de maior ou menor prestígio. Ainda segundo tal concepção existem níveis e graus de poder altamente diferenciados e determinados pelas correlações entre distintas variáveis, como por exemplo, a ascendência familiar e o capital social acumulado pelas famílias, ou ainda este último conjugado à escolha profissional e o seu decorrente acúmulo de prestígio no interior de um dado campo de atuação. Deste modo, numa visão bourdieusiana do poder, existem, no interior de uma classe, algo já dificilmente emoldurável, enormes cortes diferenciais, conferindo posições e dis-posições para as práticas. A perspectiva bourdieusiana aqui pode nos servir para pensar como os agentes sociais, dotados de habitus de classe distintos, mobilizam seletiva e racionalmente, ainda que guiados por impulsos motivadores de ordem afetiva - também eles disposições de valores e de sentidos estruturados e estruturantes -, aportes de linguagem com vistas à maximização de "lucros sócio-simbólicos".

Por esta via podemos vislumbrar a possibilidade de pensar o plano reflexivo da ação social em dupla perspectiva da memória. Uma que diz respeito ao desenvolvimento formativo do indivíduo no plano multimodal da classe, da filiação étnica, de gênero ou do sentimento de vinculação nacional; mas também pensar a existência de memórias sociais que, por seu turno, existem de modos mais ou menos autônomos em relação aos indivíduos isoladamente. As sociedades capitalistas modernas são uma das arenas mais férteis para se pensar tais diferencialidades e segmentações da vida social. Assim, a consciência pode ser vista tanto ao nível de seu processamento subjetivo e individualizado (o do tempo irreversível da durée) quanto ao nível do seu desenvolvimento histórico-processual: da nação, das tradições e de suas incansáveis ressemantizações entre as gerações nas pugnas pelo agenciamento dos recursos disponíveis.

5 Outra interessante leitura da fomentação do mito nacionalista alemão é a realizada por Zigmunt Bauman em Modernidade e Ambivalência e Modernidade e Holocausto. 
É nesta arena, marcadamente clivada e plural, transnacionais, que devemos nos deter no momento. Devemos nos questionar nesse instante sobre o fato de que o processo de integração mundial, acelerado na fase moderna do Ocidente, pela consolidação do capitalismo e de desenvolvimentos técnicos que possibilitaram um maior deslocamento dos indivíduos no globo, forneceu-nos uma configuração de produção de redes integradas, entre Estados, blocos econômicos, formas difusas de atuação política e ideológico-valorativas. Este contexto ampliado de trocas de experiências permite transmigrações físicas e sócio-simbólicas entre os espaços sociais. Isto se dera, das formas as mais diferentes: por meio de diásporas de contingentes enormes de pessoas, mediante o tráfico ou fuga de guerras, ondas de emigração de trabalhadores nos mais distintos pontos do globo, a emergência de elites transnacionais, a disseminação de redes de serviços vinculadas ao turismo e imperativos valorativos e existenciais que primam pelo consumo do diverso espécie de canibalização (absorção) da alteridade. Isto sem falar da constituição de espaços virtuais interativos em tempo real ensejados pela difusão de meios de comunicação como a internet.

O encadeamento de alguns dos fatores elencados acima constitui parte da reconfiguração significativa dos espaços sociais, bem como dos esquemas perceptivos de temporalização e espacialização. A tarefa reside, pois, pensar a formação de espaços sociais de interação formados a partir dos encontros de diferentes sujeitos sociais, tributários de tradições, valores e costumes diferenciados. A constituição de espaços necessita, de antemão, a existência de memórias sociais, mais ou menos sedimentadas pela reiteração de seus princípios elementares mediante exercícios prático-discursivos e performativos dos próprios sujeitos em suas interações cotidianas. A emergência de novos espaços se dá pari passu movimentos de rearticulação inter-subjetiva, seja pelo rearranjo propiciado pelo deslocamento de comunidades inteiras em novos contextos seja pelo caldeamento propiciado pela convivência de distintas comunidades em um mesmo contexto social.

Tomemos de empréstimo de Cassirer (2005) a sua acepção sobre os esquemas de temporalização e espacialização. Cassirer aponta para a obra de um dos fisiologistas do século XIX, Ewald Hering, segundo o qual a memória deve ser vista como "função geral de toda matéria orgânica". Ainda segundo esta teoria a memória não se restringe a um aspecto da nossa vida consciente, mas está difundida por todo domínio da natureza viva. (pg. 86). Tal teoria foi desenvolvida por R. Semon, que, ancorado nela, desenvolveu um novo esquema geral da psicologia. De acordo com a nova proposta a única possibilidade de se realizar uma psicologia científica seria através de uma biologia mnêmica. Mneme aí aparece como princípio da conservação na mutabilidade de todos os acontecimentos orgânicos. "Cada estímulo que age sobre um organismo deixa nele um "engrama", "um traço fisiológico definido"; e todas as futuras reações dependem da cadeia desses engramas, desse "complexo de engramas" conectados"6.

${ }^{6}$ A acepção psíquica de engrama denota uma "impressão duradoura deixada na mente", enquanto o conceito na fisiologia remete a uma "marca definitava deixada no sistema nervoso por um estímulo". Ambas acepções nos servirão para 
Do Bifrontismo de Jano: Notas para a reflexão sobre os processos de Reflexividade, Síntese e Re-Significação de Memórias Sociais

Logo em seguida, o autor aponta para a diferencialidade significativa do conceito de mneme, ou memória, na antropologia, pois se adotarmos a idéia de inscrição, de traço fisiológico posta na visão de Semon, se age em detrimento da dimensão propriamente "humana" da memória. Para que esta se revele é preciso outra coisa que o remanescente latente da ação anterior de um estímulo. É preciso que haja "reconhecimento" e "identificação", um processo ideacional muito complexo. As repetições de impressões anteriores não são suficientes para que a memória humana se processe; necessitam de ordenação e localização e que estejam referidas a diferentes pontos do tempo. Tal localização requer, obrigatoriamente, um esquema geral de temporalização, como ordem serial, que, ao mesmo tempo que compreende, "marca", no duplo sentido, todos os eventos individuais. A

operacionalizar, mais adiante, a análise de redes significacionais, ou planos e "esquemas de significação". Creio que o conceito de engrama como tomado de empréstimo por Cassirer em seu esquema analítico aponta para a coalescência entre estrutura e agência. O aspecto "materializável" da "estrutura", em suas disposições corpóreas, perceptivas, performativas e ideacionais se realiza mediante a retenção de esquemas gerais de percepção, compreensão e ação, que, indelevelmente, serão postos à prova nas situações de interação. Embora esses esquemas gerais sirvam de suporte básico para a reprodução da vida em sociedade com o mínimo senso de previsibilidade, espera-se dos sujeitos a habilidade e a competência para a sua gestão. Não parece ser à toa que este autor tenha desempenhado papel importante nas tentativas de resolução do problema da dualidade de estrutura tanto por parte de Pierre Bourdieu quanto por parte de Norbert Elias. Por isto por mais que tais esquemas forneçam substratos éticomorais e performativo-estéticos a re-produção da vida social não se realiza mediante mera repetição, mas por montagens e remontagens subjetivas, por processos de síntese e rearticulação dos traços e impressões sócio-culturais. Devese reiterar, contudo, que os processos de significação,subjetivação e ressemantização desencadeadas pelos sujeitos na cotidianidade não poderia se realizar sem a capacidade humana inata para a compreensão .mediante "sentidos subjetivamente visados num contexto historicamente dado", como para Weber. A tendência desencadeada pelo crescente processo de diferenciação da vida social, já apontada por Durkheim, é a de possibilitar a formação de redes cada vez mais heterogêneas. $O$ que pensar neste sentido os casos de irmãos que são educados mediante os mesmos princípios ético-morais pela família e pela escola toman no decurso de suas vidas seguirão trajetórias completamente distintas? Ou ainda, como no caso do universo religioso, aqueles sujeitos que estão diretamente influenciados primariamente por uma ideologia cristã-católica mas que ao longo de suas vidas são impactados ou influenciados por outras leituras de mundo, possibilitando-lhe, inclusive, a negação da formação primária? Interessa-nos, particularmente, como tais impressões duradouras nos esquemas sensóriomotores, em suas repercussões racionais e afetivas, são sintetizadas nas experiências de vida individuais e como nos processos de subjetivação e reinserção em distintos pontos da rede social acabam ajudando a re-tecer suas malhas e suas fronteiras. 
percepção do tempo implica o conceito de tal ordem serial correspondente àquele outro esquema que conhecemos por "espaço".

$\mathrm{Na}$ coalescência entre estes esquemas reside o problema goffmaniano da co-presença. Por assim dizer ela constitui algo como uma imaginação "estribada nas modalidades perceptivas e comunicativas do corpo". "Embora 'as condições plenas de co-presença', existam somente no contato não-mediado entre aqueles que estão fisicamente presentes, na era moderna são possibilitados contatos mediados, que permitem algumas das intimidades da co-presença, pelas comunicações eletrônicas" (Goffman apud Giddens, pg. 54).

Atenhamos-nos, no instante, aos preceitos antropológicos de reconhecimento e identificação com o intuito de pensar nos planos metafóricos e metonímicos das linguagens ressemantizadas em conseqüência dos deslocamentos espaço-temporais. Tal proposição se pauta pela tentativa de compreender os processos de deslocamento de processos mitopoéticos de seus nichos de acomodação primários. Afinal, como poderíamos pensar o processo de gestação dos candomblés no continente sul-americano sem proceder à investigação dos processos de resignificação dos antes distintos planos míticos que passam a compor no novo cenário, e em dependência das circunstâncias desumanizadoras provocadas pela escravidão, um conjunto integrado de crenças? Ao dizer isto, coloca-se em foco tanto as homologias existentes entre as formas de crenças religiosas existentes na Colônia e no Império - ou um momento de gestação - como as diferencialidades processadas no interior dos cultos de candomblé. Sem nos alongarmos demais na descrição detalhada do processo sócio-histórico que faz surgir em cena o candomblé, basta dizer que o modelo básico, ou modelo reduzido do que se entende por candomblé, decorre de uma invenção processada mediante a formação de um panteão de espíritos que, no seu continente de origem recebiam cultos isolados e locais. Não parece ser mero acaso o fato do panteão candomblecista, em grande medida, ser depositário de modelo de organização dos santos católicos e de significativa parcela de seus membros os associarem santos a orixás, por similaridades entre aspectos qualificativos que possibilitam a metonímia, ou "transnominação". Pela forte segmentação étnica existente entre os

7 Por exemplo, na expressão corriqueira "baixar no santo", ou o "santo baixou", usadas para indicar a efetivação do transe, momento de esquecimento da consciência em prol da incorporação do orixá, já há uma condensação de sentido de dois objetos, a princípio, bem distintos: santos (espécie de heróis populares católicos) e orixás (desuses anímicos e naturalistas). Por não termos tempo espaço aqui para uma apresentação mais detalhada do assunto, apenas farei menção à importância dos estudos sobre sincretismo empreendidos no Brasil durante boa parte do século XX. Especial menção deve ser conferida a Roger Bastide em sua tentativa romântica de buscar um "sentido" geral no Brasil, a partir dos processos de fusão ocasionados pelos encontros e pelo choques de processos civilizatórios. Os anseios de Bastide repercutia a busca obstinada modernista por uma expressão autenticamente nacional, sobretudo aqueles vinculados a Mário de Andrade. Ver, a este respeito Peixoto: (1999). E do próprio Bastide ver seus trabalhos sobre "sincretismo católico-fetichista" (1973) e sobre a "acomodação do positivismo no 
Do Bifrontismo de Jano: Notas para a reflexão sobre os processos de Reflexividade, Síntese e Re-Significação de Memórias Sociais

contingentes de escravos trazidos à Bahia, haviam, até o final do século XIX e o início do XX, resistentes sentimentos de vinculação étnica, ainda visualizáveis nas formas de associação política no interior de irmandades negras, ou ainda no simples hábito que negros provenientes de áreas culturais e lingüísticas tinham de se reunir em pontos e horários específicos na cidade, como nos relata Nina Rodrigues em Os Africanos no Brasil (1988). Na formação do panteão nagô, ou de sua versão jeje-nagô, desencadeia-se um processo de diferencialização dos modelos de culto candomblecistas, cujas estilizações variam entre o modelo ortodoxo e o heterodoxo. No caso dos últimos tem sobressaltado o modelo dos candomblés de caboclo e da Umbanda, com sua ênfase na brasilidade produzida e performatizada a partir de uma concepção de caldeamento de distintas influências sócio-culturais na formação nacional brasileira, em contraposição ao apelo africanista do nagocentrismo.

Os processos de síntese e recriação operados passam a constituir um sistema de crenças e valores performativos e rituais variados. Ao mesmo tempo, tais diferencialidades - nas formas de agenciamento religioso - constituem uma gramática comum, facilmente reconhecível por todos que façam parte do campo, independentemente de sua filiação no sistema no momento observado. Assim, os angoleiros precisam estar dotados da capacidade de reconhecer modos correlatos de agenciamento da magia pelos nagôs ou pelos jejes, e vice-versa. Não é incomum situações de intenso trânsito de sujeitos entre tradições variadas do candomblé, como no caso de alguém que "viria a ter o santo raspado errado, para outro orixá que não o seu, em uma nação a qual não deveria estar filiado". Situações como esta, onde alguém se deslocou de uma micro-tradição a outra, implica, necessariamente, num movimento reflexivo de releitura, por parte do sujeito religioso, como da nova comunidade que lhe acolhe e da antiga, que foi preterida, de todo o desenvolvimento sócio-humano do sujeito e das comunidades que constituem o sistema social, ou sistemas sociais em diálogo.

Obviamente, que do ponto de vista político, tais deslocamentos balizam as dimensões de poder entre as nações de candomblé, rearranjando muito sutilmente o quadro de distribuição dos vários capitais sociais acumulados ou pretendidos (no caso de novas casas) pelas unidades religiosas e suas tradições micro-nacionais correlatas. Por assim dizer, os espaços de atuação e de influências de pautas discursivas, ancoradas em versões "autorizadas" ou "desautorizadas" dos mitos, são marcados pela utilização recursiva da ancianidade e, em certos casos, do grau de "africanidade" das micro-tradições, dentre outros fatores. O poder simbólico acumulado pelas casas pode ser avaliado pela capacidade que as mesmas detêm de incutir a crença nos seus membros da legitimidade da interpretação e da atuação religiosa da mãe-de-santo ou do pai-de-santo. A dimensão da crença, do reconhecimento e validação da atuação está na contrapartida direta do nível de adesão. Um estudo a ser realizado ainda, nesse sentido, é o de avaliar se terreiros mais novos e menos influentes no meio apresentam um nível maior de evasão dos seus membros com relação àqueles mais consolidados e legitimados no campo.

Brasil e seus projetos de assimilhação e homogeneização de crenças e sentimentos" (1946). 
Diante do problema posto, por ora, esboço a interpretação de que na produção de espaços sociais religiosos como o dos candomblés, mas também no caso da igrejas evangélicas, se verificam dois traços marcantes. Por um lado as tentativas de manutenção e reprodução de alguns princípios religiosos elementares, vinculados a certas tradições, que em geral são reafirmadas mediante as práticas ascéticas e obstinadas de agentes do "núcleo duro" - mais avessos à dispersão, sobretudo aqueles que nasceram no seio da religião e sacerdotes e sacerdotisas já estabelecidos no campo. Por outro lado, existem aqueles indivíduos que são potenciais adeptos à conversão e adesão religiosas. Deste último contigente pode se depreender a possibilidade de uma análise de fluxos que colocam todos esses aportes de sentido religioso em contato, como que arrastando uma calda comum no interior de todo o mercado religioso. Os muitos fluxos e refluxos de membros entre as religiões, e destes entre lugares diferentes do globo têm proporcionado deslocamentos e ressemantizações nas próprias espacialidades e temporalizações ${ }^{8}$. O que dizer da implantação de terreiros de candomblé em outros países da América Latina, ou mesmo nos Estados Unidos e na Noruega? Seguirão eles uma gramática tão próxima assim do conjunto de traços que marcam os candomblés soteropolitanos? Ainda assim, é curioso observar que adeptos de candomblés fora de Salvador se reportem à Bahia como uma espécie de Meca para os mulçumanos, nem tão diferente assim do modo como alguns candomblecistas em Salvador se reportam à África como pedra fundamental. Em parte podemos dizer que o argumento, como esboçado até aqui pode sugerir entradas profícuas para o entendimento dos processos de integração e diferenciação a um nível global. Ao mesmo tempo em que algumas gramáticas tendem a se esborrar internacionalmente verificamos em meio a este processo os efeitos localizados e muito específicos de tais espraiamentos significacionais. Assim, novas formas de territorialidade tendem a se desenvolver, no bojo dos entrecruzamentos de memórias sociais processadas por agentes que estejam em situações que possibilitem a convivência, diálogo, pugna, de alteridades.

\section{Pluralidade, trânsitos religiosos e sintetizações de memórias}

Um processo correlato, verificado em várias partes do mundo e também no Brasil, já há algum tempo, diz respeito à catalisação de crenças e cosmologias distintas, processadas por indivíduos, sem a adesão plena a uma corrente religiosa específica. Alguns dos motivadores estão ora na busca de auto-explicação pessoal e

8 No caso dos candomblés e de outros fenômenos similares, em outros locais, verificou-se ao longo do século XX significativas modificações das formas de marcação do tempo. Uma delas é aquela que diz respeito à redução no tempo de iniciação por que passa um filho ou filha-de-santo. Se antes a reclusão poderia durar até meses, atualmente, em muitos casos, o processo de mataforfose iniciática foi reduzido significativamente, em decorrência da impossibilidade de dispensar tanto tempo por motivos profissionais ou na ausência de quem custei a sua estadia no barracão. 
Do Bifrontismo de Jano: Notas para a reflexão sobre os processos de Reflexividade, Síntese e Re-Significação de Memórias Sociais

do mundo circundante, ora na satisfação de anseios afetivo-simbólicos ou, simplesmente, por participação. Assim sintetiza Lísias Negrão (2008: 128) sobre algumas das prerrogativas contrárias a um modo de vida religioso institucionalizado, sacramental e assentadas na obrigação de participação regular das congregações :

Seu oposto lógico está na construção de religiões individualizadas cujo oficiante é o próprio leigo: "Minha religião eu mesmo faço". Essa atitude religiosa pósmoderna também remete ao reencontro com o primordial, pois trata-se do retorno à situação de autoconsumo que, segundo Bourdieu (1974), teria precedido ao monopólio sacerdotal dos bens de salvação estabelecido no momento da plena constituição do campo religioso. Nesse reencontro do pós com o prémoderno, cada um seleciona as crenças que lhe pareçam mais plausíveis e pratica isoladamente os rituais que the pareçam mais eficazes. Essa recusa do institucional decorre da recusa da "verdade pronta", imposta pelos dogmatismos e exclusivismos. A religião é vista, e por isso valorizada, como uma busca constante em que o indivíduo vai se aprofundando no que lhe parece fazer sentido. Trata-se de uma atitude religiosa ativa, embora individual.

O mito moderno ancorado nos preceitos do resguardo da individualidade e da constituição de leques de auto-consumo dá o tom também no mundo do consumo do sagrado. Pensar num esquema de "individualismo religioso" pode nos ajudar a entender, em nível extenso, o que se processa local e globalmente. Ainda parafraseando Negrão, as condições dadas pela realidade plural das religiões na modernidade é o que possibilita que haja "duplicidades", "multiplicidades" e "construções religiosas personalizadas" (op. cit. Pg. 129).

Acrescentemos a este argumento a proposta de Stolz (2009: 347) em distinguir religiosit de religion. No seu modo de entender, religiosidade se refere às emoções, crenças, ações e preferências individuais, que se referem à existência da religião. Já o termo "religião" deve ser usado para se referir aos sistemas simbólicoculturais que fornecem respostas para os problemas de contingências e significados por alusão a uma realidade transcendente que está agindo na cotidianidade da vida e que não pode ser de todo controlada. Falar de religião, neste sentido, é falar de um conjunto mais ou menos homogêneo de crenças e práticas rituaisdiscursivas, ainda que marcadamente diversificada nas possibilidades de escolha, interpretações e modos de sentir. Tal conjunto, obviamente, só pode ser pensado ideal-tipicamente, como que sustentado por uma espécie de corrente mais ou menos sedimentada de princípio morais e éticos reiteradas na cotidianidade por seus membros orgânicos. 
Colocado nesses termos, não falamos de outra coisa senão da relação entre estabilidade e instabilidade. A função dos ritos, exigidos pela comunidade religiosa, privados ou coletivos, reside na necessidade de afirmar, reproduzir e manter em equilíbrio o próprio sistema. No caso dos ritos sacrificiais, como posta na visão de René Girard, por exemplo, o que se pode deles entender, em linhas gerais, é que são formas de contenção da "violência primordial", postas num sistema dinâmico de trocas e compensações, nas relações estabelecidas entre os deuses e os homens.

E o que pensar, então, das experiências pessoais dos "desgarrados", que estão em busca de compensações existenciais ou espirituais, e que não se agarrarão de pronto a uma comunidade religiosa? Por meio desses trânsitos e percursos desses mutantes religiosos pelos diversos templos, terreiros, centros e outros locais de culto é que vão se agregando crenças diversas em recriações sintéticas e racionalmente auto-explicáveis. Além do caráter propriamente subjetivo existe um aspecto objetivo sobre o qual devemos nos deter. Não é senão aquele concernente à extrapolação dos regimes discursivos próprios às formações religiosas para além de suas fronteiras, nas mediações promovidas nas relações dos "de dentro" com os "de fora". E, talvez, nestes engates entre "os de dentro" e os "de fora" possamos refletir acerca de espaços de negociações sutis e de agenciamentos possíveis da adesão a pautas discursivas e interpretativas. Esses espaços entre-abertos de negociação constituem canais importantes de veiculação e negociação do mercado religioso. Situações como as de quando alguns sujeitos enfrentam problemas difíceis e não encontram soluções nos canais institucionalizados, ou a eles não têm acesso são heurísticas nesse tocante. Numa situação típica como esta, muitas pessoas são convidadas ou convencidas, por parentes, amigos, namorado(a), a visitar outros locais de culto. Nesse caso, ainda, outros fatores, tais como os novos modos de comunicação, interação e aprendizagem disponibilizados a pessoas com maior nível de instrução e renda, que podem tomar conhecimento de seitas e crenças outras, não institucionalizadas, por meio de livros e meios de comunicação como a internet.

Poderíamos, assim, distinguir dois grupos de mutantes: aqueles que percorreram e foram marcados por distintas religiões e crenças, mas que experimentaram algum nível de adesão e prática religiosa mais ou menos estável e aqueles que transitam entre crenças e concepções variadas, buscando um substrato mais ou menos homogêneo e coerente e que podem vir, ou não, a se filiar e se estabelecer em alguma doutrina, num momento futuro. De todo modo, é possível depreender disto que tanto num caso como no outro, os trânsitos acarretam planos de reconfiguração das memórias individuais além de ressemantizações constantes, embora sutis, dos conteúdos cosmológicos dos diversos sub-campos religiosos, dadas nas relações cotidianas e intersubjetivas.

Entre o público que oscila entre religiões distintas mas que está em busca de adesão reside o problema teórico da escolha racional. Frigério (2008: 20-22), em seu artigo recente busca mostrar uma idéia geral das reformulações realizadas até então em torno desta teoria, sobretudo na vertente de uma economia religiosa, como nas obras de Rodney Starke, George Finke, Laurence Iannaccone e Boudon. Interessante apontar para a retomada do conceito mais matizado de Boudon (1993), 
Do Bifrontismo de Jano: Notas para a reflexão sobre os processos de Reflexividade, Síntese e Re-Significação de Memórias Sociais

o de "racionalidade subjetiva" - diretamente ancorado no modelo compreensivista weberiano $^{9}$-, com o intuito de apontar para o lado intuitivo da racionalidade humana. Boudon apontaria assim para uma espécie de bom senso que balizaria a escolha a uma determinada visão religiosa mediante avaliação de conjecturas plausíveis, dos custos e da maximização destes em recompensas.

Aceito a sugestão de Frigério de que esta teoria subjetiva da racionalidade caminha pari passu com o axioma do interacionismo simbólico, segundo o qual para compreender os comportamentos humanos se faz necessário analisar como os atores interpretam e definem as situações nas interações. Seria então nessas situações, rituais, de consumo de serviços religiosos curativos, profiláticos e divinatórios, por exemplo, que se processaria o ato de escolha ou recusa e adesão a uma outra cosmovisão por parte dos atores sociais. E aqui apenas pensando idealtipicamente em situações liminares. No fluxo incessante da vida e nesses eventos decisivos pode se processar reflexivamente os fatores compreensivos que possibilitam a escolha.

Importante dizer neste ponto que aspectos propriamente afetivos atuam decisivamente na escolha, como por espécie de acomodações compreensivas, ou exercícios sintéticos de compreensão, onde os matizes específicos de sua trajetória e de suas experiências afetivas e valorativas correlatas pautam a adesão. A racionalidade se realizaria, assim, portanto, no ponto intersticial entre memória valorativa e afetiva e o plano reflexivo da ação. Se retomarmos aqui aquela acepção mobilizada anteriormente sobre os traços e impressões duradouras estribadas nas experiências sensório-motoras (os engramas) e pensarmos conjugadamente no senso de segurança ontológica básica (o selfio) teremos um nó interessante para acompanhar um tal esquema da reflexividade processada nas ações racionais de escolhas. Ainda pensando sobre a noção de memória em Cassirer, das suas prerrogativas elementares de reconhecimento e identificação potencializamos uma visada sobre alguns dos fatores motivadores das escolhas dos agentes, pois muitos tendem a optar por religiões com visões compatíveis; pelo mesmo prisma pode-se depreender o tipo de síntese optada pelas articulações interpretativas daqueles bricoleurs avessos à adesão institucional. Em tempos de liberalismo do mercado religioso podemos depreender então, aceitando a leitura de Frigério, que a

9 Como salientado por Game (1996: 388) o "sentido" se define entre o racional e o irracional. A questão da inteligibilidade e do significado sofre determinações marcadamente afetivas. Assim Weber apontaria para a necessidade da sociologia "to take into account the determinative role of emotions, psychisical elements, and phenomena such as mortality and memory" (ibidem).

10 Dereck Layder (2004) aponta em sua obra para a importância que o self desempenha no exercício de auto-controle do indivíduo no sentido de manter a integridade emocional do mesmo. O continuum do processo reflexivo orientado e mediado pelo self, no sentido de manter o equilíbrio das carências emocionais que lhe constituem, está entremeado de medidas plásticas e auto-monitoradas dirigidas a busca de satisfação das pressões para o alívio emocional. Canais convidativos e apelativos no sanamento de incertezas e sensações extremas e variadas de sofrimento têm sido uma das mais importantes formas de conversão. 
avaliação contínua (monitoração reflexiva do self) dos bens mágicos e religiosos que estão recebendo a cada momento e em cada lugar de crença, constitui o motor da "carreira religiosa" do indivíduo. Isto nos ajudaria a melhor compreender o intenso trânsito de muitos evangélicos por distintas igrejas ou de "afro-brasileiros" e umbandistas entre nações, doutrinas e variantes religiosas correlatas. Tal concepção de análise pode nos ajudar a entender os processos de conversão, reconversão ou passagem religiosas como a mobilização de esforços cognitivos, de sintetizações monitoradas pelo self, que envolvem, invariavelmente, custos emocionais e materiais.

O Equacionamento reflexivo, avaliador e interpretativo, das demandas, afetiva ou materiais, e dos meios de satisfação e acomodação do self acaba por dar o tom da escolha, assim como configura a forma de inserção e de participação do sujeito no interior de uma comunidade religiosa. Os estudos de conversão e filiação que apontam para "opções" entre várias religiões não contrapõe diretamente a idéia posta na maximização dos ganhos pleiteados pelo indivíduo na conversão. Mas devemos ter em mente que não existe um momento preciso de decisão. Antes a opção se dá no continuum da experiência e da participação religiosa do indivíduo no interior de uma comunidade, durante a qual a avaliação processual e ininterrupta das muitas vicissitudes que marcam o seu decurso serve de recursos à avaliação entre permanência, saída resignificação ou migração de comunidade e cosmovisão.

E nesse sentido vale fazer referência à obra de Goffman (2002 [1959]), sobretudo no seu aspecto fenomenológico posto na concepção de alteridade performativa. Por esta via, mediante a qual o autor pensa a ordem e o contexto interativo pela encenação (representação) dos atores habilmente dotados de competências para ocultar, dissimular e manipular situações e resguardar e conter os possíveis desequilíbrios do self. Vejamos o que diz Smith (2006: 398-99) acerca do esquema goffmaniano:

"Goffman noted the existence of what might be paraphrased as "Wittness's Advantage" writing of "a fundamental assimetry ... in the communication process" that provide individuals control over expressions given and given off. Even as skillful individuals could, through feigning, manipulate given off expressions to counter this imbalance, Goffman suggests that in the "potentially infinite cycle of concealment, Discovery, false revelation, and rediscovery", that might result, the dice are loaded in favor the asymmetry because human are better at "piercing an individuals efforts at calculated unintentionality than they are at manipulating their own behavior. It seems deeply embedded into the impression manegement thesis is recognition of the edge the other has over the individual." 
Do Bifrontismo de Jano: Notas para a reflexão sobre os processos de Reflexividade, Síntese e Re-Significação de Memórias Sociais

Por meio disto podemos pensar novamente acerca dos esquemas gerais perceptivos de temporalização e espacialização resguardados nas complexas cadeias de engramas que constituem o próprio senso de orientação básico e de segurança ontológica do self. No fluxo dos eventos cotidianos, que marcam a história biográfica do indivíduo, na sua efetiva participação em contextos interativos, são requeridos deles a posse ou a disponibilidade para a absorção de novos princípios básicos de ação. Nas séries de instantes nos quais os indivíduos desenvolvem as competências para articular sua bagagem experencial acumulada com modos de atuação e participação que exigem releituras e rearticulações constantes da sua performatividade e relação com os outros.

\section{Considerações finais}

Há de supor, assim, que nas situações de deslocamento dos indivíduos entre distintas cosmovisões religiosas estejam em ação processos abertos de ressemantização das experiências individuais. Mas também das pautas discursivas e interpretativas que constituem as memórias sociais, diretamente animadas por anseios de auto-regulação do self e a busca de satisfação de demandas desencadeadas por assimetrias emocionais, comunicativas e de poder socialmente determinadas.

Nas muitas releituras operadas no seio de tradições religiosas, mas também de discursos nacionais, podemos entrever processos de operação sintéticoideacionais e representacionais dos agentes como forma de manutenção ou reequilíbrio do self ou ainda com vistas à maximização de "lucros simbólicos", que pode ser vertido na aquisição de prestígio no interior das suas comunidades discursivas. São nesses movimentos de deslocamentos sutis no plano das intersubjetividades que se operam transformações e re-criações mais ou menos discretas das pautas discursivas e que redefinem gradual e ininterruptamente as fronteiras demarcatórias dos espaços de atuação no mercado de produção e consumo de bens simbólicos.

São nas pugnas e jogos de linguagem interinstitucionais e intersubjetivos que podemos também verificar e analisar a distribuição de poder entre os campos, sub-campos e entre suas membresias. Nas disputas por adeptos e por meio de formas diferenciadas de satisfação das ansiedades individuais reside o motor entre produção e consumo dos bens religiosos. 


\section{Bibliografia}

Baldwin. John D. Habit, Emotion, and Self-Conscious. In: Sociological Perspectives, Vol. 31, No. 1 (Jan., 1988), pp. 35-57. Stable URL: http://www.jstor.org/stable/1388950. Acessed: 28/07/2009.

BASTIDE, Roger \& URANGA, Emilio. El Positivismo Brasileno y la Incorporacion del Proletariado de Color a la Civilizacion Occidental. Revista Mexicana de Sociología, Vol. 8, No. 3 (Sep. - Dec., 1946), pp. 371-388. Stable URL: http://www.jstor.org/stable/3537173. Acessed: 28/07/2009

2001.

O Candomblé da Bahia: rito nagô. São Paulo: Companhia das Letras,

“Contribuição ao Estudo do Sincretismo Católico-Fetichista." In: Estudos Afro-Brasileiros. São Paulo: Editora Perspectiva, 1973.

BERGSON, Henri. Matéria e Memória: ensaio sobre a relação do corpo com o espírito. São Paulo: Martins Fontes, 2006.

BOURDIEU, Pierre. A Distinção: crítica social do julgamento. São Paulo: Edusp; Porto Alegre, RS: Zouk, 2008.

CASSIRER, Ernst. Ensaio sobre o Homem: introdução a uma filosofia da cultura humana. São Paulo: Martins Fontes, 2005.

FRIGERIO, Alejandro. O paradigma da escolha racional: mercado regulado e pluralismo religioso. Tempo soc., São Paulo, v. 20, n. 2, Nov. 2008 . Available from <http://www.scielo.br/scielo.php?script=sci_arttext\&pid=S010320702008000200002\&lng=en\&nrm=iso $>$. Access on 26 July 2009. doi: $10.1590 /$ S0103-20702008000200002.

GARFINKEL, Harold. "What is Ethnomethodology?". In: Studies in Ethnomethodology. Englewood Cliffs, NJ: Prentice-Hall

Game, Ann. 1997. "Sociology's Emotions." Canadian Review of Sociology $\mathcal{E}$ Anthropology 34, no. 4: 385-399. SocINDEX with Full Text, EBSCOhost (accessed July 28, 2009).

GIDDENS, Anthony. A Constituição da Sociedade. São Paulo: Martins Fontes, 1989.

"Garfinkel, Etnometodologia e Hermenêutica". In: Política, Sociologia e Teoria Social. São Paulo: Fundação Editora da UNESP. , 1998.

GOFFMAN, Erving. A Representação do Eu na Vida Cotidiana. 12. ed. Petropolis: Editora Vozes Ltda, 2002. 
Do Bifrontismo de Jano: Notas para a reflexão sobre os processos de Reflexividade, Síntese e Re-Significação de Memórias Sociais

HOCHSCHILD, Arlie R. The Managed Heart: commercialization of human feeling. Berkeley: University of California Press, 1983.

Sewell Jr., W. (1992, July). A Theory of Structure: Duality, Agency, and Transformation. American Journal of Sociology, 98(1), 1. Retrieved July 27, 2009, from SocINDEX with Full Text database.

KOSELLECK, Reinhart. Futuro Passado: contribuição à semântica dos tempos históricos. Rio de Janeiro: Contraponto \& Editora PUC Rio. s/d.

LAYDER, Derek. 2004. Emotions in social life - the lost heart of society. Londres, Thousand Oaks e Nova Déli: Sage, 2004.

MACKAY, Robert. Garfinkel and Ethnomethodology. In: The Canadian Journal of Sociology. Vol. 12, n. 4, 1987. pp. 409-411. Stable URL: www.jstor.org/stable/3340947

NEGRAO, Lísias Nogueira. Trajetórias do sagrado. Tempo soc., São Paulo, v. $\begin{array}{llll}20, & \text { n. 2, Nov. 2008.Available }\end{array}$ www.scielo.br/scielo.php?script=sci arttext\&pid=S0103-

20702008000200006\&lng=en\&nrm=iso. Access on 27 July 2009. dói: 10. 1590/S010320702008000200006.

NINA RODRIGUES, Raimundo. Africanos no Brasil. 7. ed. Brasília: Editora Universidade de Brasília, 1988.

PEIXOTO, Fernanda. “Diálogo Interessantíssimo: Roger Bastide e o Modernismo." Rev. bras. Ci. Soc., São Paulo, v. 14, n. 40, June 1999. Available from www.scielo.br/scielo.php?script=sci arttext\&pid=S0102- acesso n 28 July 2009. dói: 10.1590/S0102-69091999000200008.

SASSEN, Saskia. A Sociology of Globalization. University of Chicago and London School of Economics. 2006.

SMITH, Gregory W. H. Enacted Others. Specifying Goffman's Phenomenological Omissions and Sociological Accomplishments. In: Human Studies, Vol. 26: pgs. 397-415. 2006. Doi: 10.1007. s10746-005-9006-1.

Stolz, J. (2009, June). Explaining Religiosity: towards a unified theoretical model. British Journal of Sociology, 60(2), 345-376. Retrieved July 27, 2009, doi:10.1111/j.14684446.2009.01234.x 